\title{
ESTABILIDADE DE HÍBRIDOS DE QUIABEIRO COM BASE EM DESCRITORES AGRONÔMICOS DE INTERESSE ECONÔMICO
}

\author{
André Pugnal Mattedi ${ }^{1}$, Bruno Soares Laurindo ${ }^{2 *}$, Derly José Henriques da Silva ${ }^{3}$, Carlos Nick Gomes ${ }^{4}$, \\ Leonardo Lopes Bhering ${ }^{5}$, Moacil Alves de Souza ${ }^{6}$
}

\begin{abstract}
RESUMO - Os objetivos foram estudar o desempenho per se, avaliar a interação genótipos por ambientes (GxA) e identificar híbridos de quiabeiro com estabilidade fenotípica. Foram avaliados os híbridos, AGR 04, AGR 08, AGR 11, AGR 15, AGR 18, AGR 19, AGR 28, AGR 32 e três testemunhas comerciais: Santa Cruz 47, TPX 903 e TPX 4460 nos municípios de Santo Antônio de Posse - SP e Guimarânia - MG. Índice de precocidade, número de frutos por planta; massa média dos frutos e massa total dos frutos por planta foram avaliados. Estudo da interação genótipos x ambientes, teste Tukey a 5\% de probabilidade para comparação de médias em cada experimento e estudo da estabilidade fenotípica foram realizados. Houve significância a $5 \%$ de probabilidade pelo teste F para os fatores avaliados. Entre os híbridos avaliados foi possível observar diferentes desempenhos nos ambientes estudados. Os híbridos AGR 28 e AGR 32 obtiveram as maiores médias para todas as variáveis de interesse econômico avaliados, e destacaram-se pelo ótimo desempenho per se em cada ambiente, pelo desempenho igual entre os ambientes e pela alta estabilidade fenotípica. Estes híbridos podem ser indicados para o cultivo em regiões representativas dos locais onde os experimentos foram conduzidos.
\end{abstract}

Palavras chave: Abelmoschus esculentus (L.) Moench, avaliação de cultivares, interação genótipo x ambiente.

\section{OKRA HYBRIDS STABILITY BASED ON AGRONOMIC DESCRIPTORS ECONOMIC INTEREST}

\begin{abstract}
The aims of this work were study the per ser performance, evaluate genotype by environment interaction $(G x E)$ and identify okra hybrids with phenotypic stability. Were assessed the hybrids AGR 04, AGR 08, AGR 11, AGR 15, AGR 18, AGR 19, AGR 28, AGR 32 and three commercial witness: Santa Cruz 47, TPX 903 e TPX 4460 on Santo Antônio de Posse - SP and Guimarânia - MG. Precocity index, number of fruits per plant; mean mass of fruits and total mass of fruits per plant were evaluated. Studies of interaction genotypes x environments, Tukey test at $5 \%$ probability for each experiment and study of phenotypic stability were performed. There was a significance of $5 \%$ of probability by the F test for the factors evaluated. The AGR 28 and AGR 32 hybrids obtained the highest averages for all variables of economic interest evaluated, and stood out for the optimum performance per se in each environment, for the equal performance between the environments and the high phenotypic stability. These hybrids may be indicated for cultivation in regions representative of the sites where the experiments were conducted.
\end{abstract}

Keywords: Abelmoschus esculentus (L.) Moench, cultivars evaluation, genotype x environment interaction.

\footnotetext{
${ }^{1}$ Universidade Federal de Viçosa, Departamento de Fitotecnia, e-mail: andremattedi@gmail.com

${ }^{2}$ Universidade Federal de Viçosa, Departamento de Fitotecnia, e-mail: brunosoareslaurindo@gmail.com

${ }^{3}$ Universidade Federal de Viçosa, Departamento de Fitotecnia, e-mail: derly @ ufv.br

${ }^{4}$ Universidade Federal de Viçosa, Departamento de Fitotecnia, e-mail: carlos.nick@yahoo.com.br

${ }^{5}$ Universidade Federal de Viçosa, Departamento de Biologia Geral, e-mail: leonardo.bhering@ufv.br

${ }^{6}$ Universidade Federal de Viçosa, Departamento de Fitotecnia, e-mail: moacil@ufv.br

${ }^{*}$ Autor correspondente.
} 


\section{INTRODUÇÃO}

$\mathrm{O}$ fruto do quiabeiro (Abelmoschus esculentus (L.) Moench) possui grande importância alimentar, devido aos elevados níveis de proteínas e minerais (Yuan et al., 2014). As condições climáticas do Brasil, especialmente das regiões nordeste, centro-oeste e sudeste, favorecem o cultivo do quiabeiro, principalmente por agricultores familiares (Aguiar et al., 2013). A precocidade aliada ao longo período de colheita, torna a cultura uma boa alternativa de renda para o agricultor familiar, além de gerar mão de obra nas operações de colheita, classificação e embalagem dos frutos (Sediyama et al., 2009).

O sucesso dessa atividade econômica está associado a programas de melhoramento genético, que tem como principal objetivo o desenvolvimento de novas cultivares adaptadas às diversas condições de cultivo, visando contornar dificuldades relacionadas às diferentes regiões edafoclimáticas que estão sendo cultivadas (Nunes et al., 2006). A criação de novas cultivares é uma alternativa sustentável, pois, contribui para aumentos de produtividade e estabilidade de produção, sem custos adicionais aos agricultores (Polizel et al., 2013).

Em olericultura uma cultivar estável é altamente desejável, porque a demanda por produtos é grande durante todo o ano, e diversas cultivares não têm a capacidade de produzir ininterruptamente (Paiva \& Costa, 1994).

A existência de desempenho diferenciado das cultivares com a variação ambiental está relacionada à existência de interação entre genótipos e ambientes (GxA), e a identificação de cultivares para quiabeiro com baixos valores para esta interação é necessária para garantia de boas colheitas com o mínimo de riscos (Adele et al., 2008).

Neste contexto, medidas que minimizem o efeito da interação são necessárias. Uma das alternativas mais empregadas é a utilização de cultivares com elevadas adaptabilidade e estabilidade fenotípica (Nunes et al., 2002). Como consequência, é necessário à instalação de experimentos em mais de um local, ou sob diferentes ambientes para seu estudo, a fim de identificar cultivares com comportamento previsível e que seja responsivo ás variações ambientais, em condições específicas ou amplas (Cruz et al., 2012).
Um método comumente utilizado entre os melhoristas é o parâmetro de estabilidade proposto por Wricke (1965), também denominado método da "ecovalência", sendo sua estimativa representada por Wi, onde o genótipo mais estável será aquele que possuir valores de Wi próximos à zero.

Os objetivos com o presente estudo foram avaliar a interação genótipos por ambientes e identificar híbridos com estabilidade fenotípica em diferentes ambientes, baseando-se em descritores agronômicos de interesse econômico.

\section{MATERIAL E MÉTODOS}

Os experimentos foram conduzidos nas estações experimentais da Empresa Agristar do Brasil Ltda, localizadas nos municípios de Santo Antônio de Posse -SP (22 36' 24" S, 46 92' 05" We $661 \mathrm{~m})$, clima subtropical úmido (classificação climática de Köppen do tipo Cfa), com temperatura média anual igual a $19.6^{\circ} \mathrm{C}$ e precipitação média anual de 1356 mm, e Guimarânia - MG (18 84' 29" S ; 46 79' 05" W e 900 m), clima tropical com estação seca (classificação climática de Köppen do tipo Aw), a temperatura média anual é $22.2^{\circ} \mathrm{C}$ e a precipitação média anual igual 1471.

Para ambos experimentos utilizou-se o delineamento de blocos ao acaso, com três repetições e cinco plantas por parcela, e a parcela útil foi constituída pelas três plantas centrais. Os experimentos foram realizados no período compreendido entre setembro de 2013 e janeiro de 2014.

A semeadura foi realizada em bandejas de 128 células, que continham substrato comercial para hortaliças, e o transplantio feito para o campo no espaçamento de 1,0 x $0,4 \mathrm{~m}$. Foi utilizada irrigação por gotejamento, e os demais tratos culturais foram realizados de acordo com o recomendado para a cultura (Trani et al., 2012).

Foram avaliados onze tratamentos, sendo: oito híbridos $\mathrm{F}_{1}$ 's, AGR 04, AGR 08, AGR 11, AGR 15, AGR 18, AGR 19, AGR 28 e AGR 32 provenientes do cruzamento entre acessos do Banco de Germoplasma de Hortaliças da Universidade Federal Viçosa e três testemunhas comerciais: Santa Cruz 47 (cultivar de linha pura), TPX 903 e TPX 4460 (cultivares híbridas).

Os descritores agronômicos de interesse econômicos avaliados foram: Índice de Precocidade (\%) - razão entre a soma das massas de todos os frutos 
produzidos nas seis primeiras colheitas e a massa total de frutos, multiplicada por 100; Número de frutos por planta; Massa média dos frutos (g) e Massa total dos frutos por planta $(\mathrm{g})$.

Os dados de cada experimento (Santo Antônio de Posse - SP e Guimarânia - MG) foram submetidos à análise de variância individual para cada local, e as médias comparadas pelo teste de Tukey a 5\% de probabilidade. Foi realizada a análise de variância conjunta dos experimentos para o estudo da interação genótipos $\mathrm{x}$ ambientes para os descritores de interesse econômico (Cruz et al., 2012).

As estimativas dos parâmetros de estabilidade foram obtidas conforme o método propostos por Wricke (1956), sendo o parâmetro de estabilidade Wi também denominado de "ecovalencia" estimado decompondose a soma de quadrados da interação G x A nas partes devidas a genótipos isolados, e os híbridos com $\mathrm{W}_{\mathrm{i}}$ $=0$ são aqueles com maior estabilidade. A partição é feita usando-se:

$$
W_{i}=r \sum_{j} \hat{G}_{i j}^{2}=r \sum_{j}\left(\bar{y}_{i j}+\bar{y}_{i .}+\bar{y}_{. j}+\bar{y}_{. .}\right)^{2}
$$

em que:

$\bar{y} i j:$ média do genótipo i no ambiente $\mathrm{j}$;

$\bar{y} i$ ::média do genótipo i;

$\bar{y} \cdot j:$ média do genótipo $\mathrm{j}$;

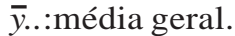

Todas as análises de variância individual e conjunta, assim como estabilidade foram realizadas utilizando o programa computacional Genes (Cruz, 2013).

\section{RESULTADOS E DISCUSSÃO}

Pela análise de variância conjunta, é possível observar que os efeitos de ambientes e híbridos foram significativos $(\mathrm{P} \leq 0,05)$ para os descritores quantitativos de interesse econômico: Índice de Precocidade; Número de frutos por planta; Massa média dos frutos e Massa total dos frutos por planta (Tabela 1), indicando inconsistência no desempenho dos híbridos diante das variações ambientais (Ramalho et al., 2012).

Paiva \& Costa (1994), trabalhando com avaliação de onze cultivares de quiabeiro e vinte híbridos recíprocos, também observaram interação dos genótipos em dois ambientes. Aexistência de interação evidencia a necessidade de avaliação dos híbridos em vários ambientes para que se possa ter melhor segurança na indicação dos melhores híbridos. A avaliação desta interação é importante, pois existe à possibilidade do melhor genótipo de um ambiente não o ser em outro (Buratto et al., 2007).

Mesmo existindo mudança na classificação dos híbridos em decorrência da variação ambiental, as interações híbridos x ambientes devem ser consideradas nos programas de melhoramento, pois influenciam no processo de seleção ou recomendação de cultivares. Assim sendo, uma vez constatada interação, deve-se sempre procurar amenizar o seu efeito sobre a manifestação fenotípica, e uma das possibilidades é a identificação de híbridos que associem bons comportamentos per se com maiores estabilidades (Nunes et al., 2006).

Para o descritor Índice de Precocidade, foi destacado o híbrido AGR 32 que obteve ótimo desempenho per se para cada ambiente e desempenho igual entre os ambientes, com alta estabilidade, $\mathrm{W}_{\mathrm{i}}=0,58$ (Tabela 2), com valores similares às testemunhas TPX 903 e

Tabela 1 - Resumo da análise de variância conjunta para os descritores de interesse econômico de híbridos de quiabeiro, avaliados em diferentes ambientes

\begin{tabular}{|c|c|c|c|c|c|}
\hline \multirow{2}{*}{ Fonte de variação } & \multirow{2}{*}{$\mathrm{GL}^{1}$} & \multicolumn{4}{|c|}{ Quadrado Médio } \\
\hline & & $\mathrm{IP}^{2}$ & $\mathrm{Nfr}^{2}$ & $\mathrm{MMF}^{2}$ & $\mathrm{MTF}^{2}$ \\
\hline Bloco/ambiente & 4 & 23,08 & 22,14 & 10,38 & 24803,7 \\
\hline Ambiente (A) & 1 & $712,42 *$ & $02,63 *$ & $0,57 *$ & $18,46^{*}$ \\
\hline Híbridos $(\mathrm{H})$ & 10 & $89,68 *$ & $54,71 *$ & $5,85^{*}$ & $16766,5^{*}$ \\
\hline HxA & 10 & $19,68 *$ & $22,91 *$ & $1,52 *$ & $8492,8 *$ \\
\hline Resíduo & 40 & 38,12 & 11,27 & 1,55 & 5661,1 \\
\hline Média & & 12,90 & 30,3 & 17,87 & 542,06 \\
\hline $\mathrm{CV}(\%)$ & & 47,84 & 11,08 & 6,97 & 13,88 \\
\hline
\end{tabular}

* significativo a $5 \%$ de probabilidade pelo teste F. ${ }^{1}$ Grau de liberdade. ${ }^{2}$ IP: Índice de precocidade (\%); Nfr: Número de frutos por planta; MMF: massa média dos frutos (g); MTF: massa total de frutos por planta (g). 
Tabela 2 - Comportamento per se e estimativas do parâmetro de estabilidade (Wi) estimados segundo modelo de estabilidade de Wricke (1965), para híbridos de quiabeiro avaliados em São Paulo e Minas Gerais

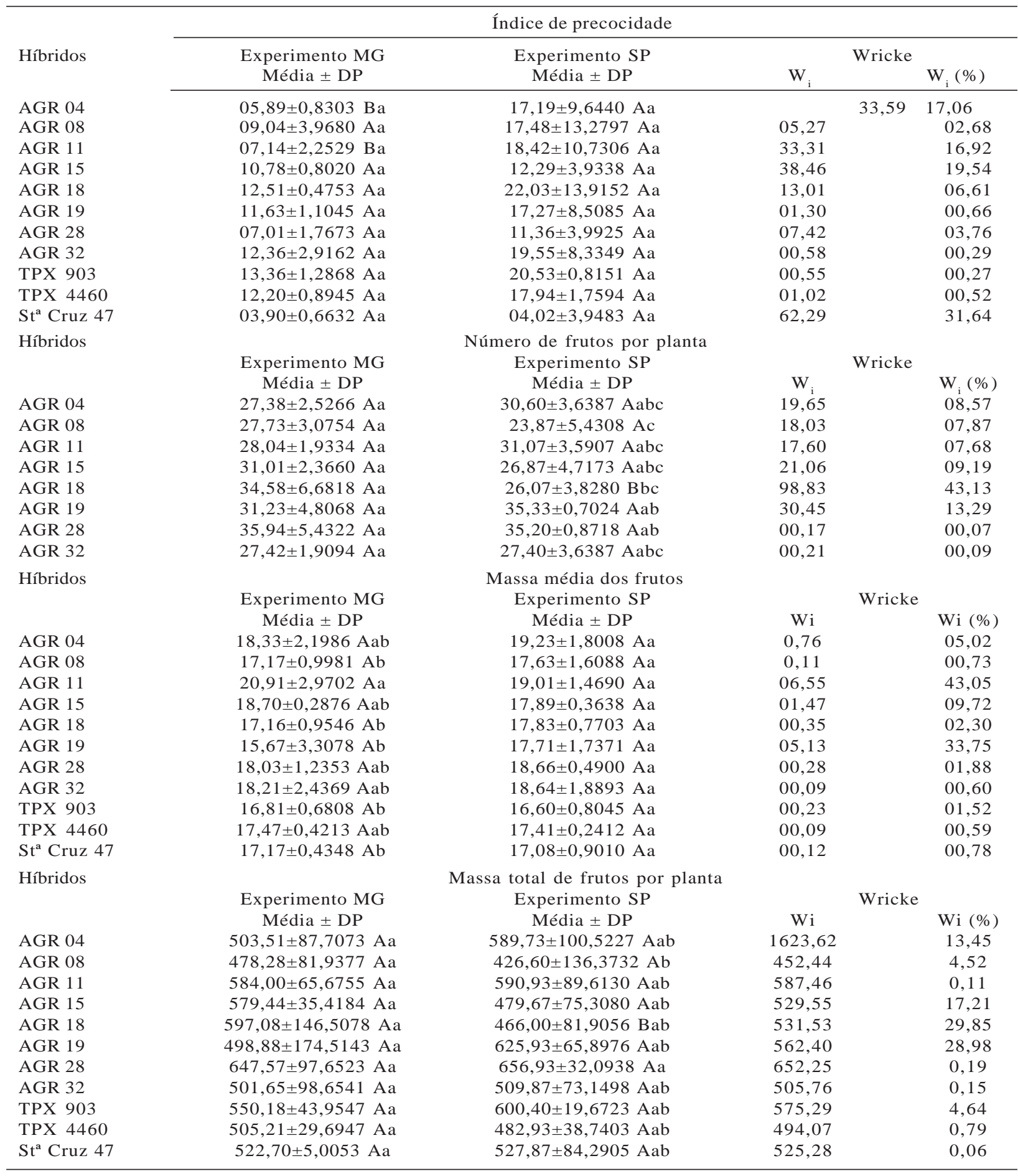

Médias seguidas pelas mesmas letras maiúsculas na horizontal e minúscula na vertical não diferem estatisticamente entre si a 5\% de probabilidade pelo teste de Tukey. DP = Desvio Padrão. 
TPX 4460, que possuem alta precocidade. $\mathrm{O}$ índice de precocidade é uma variável importante, pois, genótipos que florescem primeiro proporcionam colheitas mais precoces e ampliam o período de frutificação e o número de frutos por planta (Medagam et al., 2012). Paiva \& Costa (1998) verificaram correlação significativa entre maturação e produção total de frutos de quiabeiro, e relataram que provavelmente a seleção de plantas precoces - aquelas que alcançam os $10 \%$ da produção total em menor número de dias e menor valor quanto à maturação aumente a produção de frutos.

Nos híbridos AGR 08, AGR 18, AGR 19 e AGR 28 foram observados bons desempenhos per se para cada ambiente e comportamentos similares entre os ambientes, com boa estabilidade. Enquanto que os híbridos AGR 04 e AGR 11 tiveram comportamentos per se diferentes entre os ambientes e baixa estabilidade, com altos valores de $\mathrm{W}_{\mathrm{i}}$, assim como a testemunha Santa Cruz 47, podendo ser indicados para ambientes específicos.

Para o número de frutos por planta, os híbridos AGR 28 e AGR 32 se destacaram por possuírem ótimos desempenhos per se para cada ambiente, assim como comportamentos similares entre os ambientes e alta estabilidade, com baixos valores de $\mathrm{W}_{\mathrm{i},}$ junto com as testemunhas TPX 4460 e Santa Cruz 47. Os híbridos AGR 08 e AGR 18 para o experimento conduzido em SP tiveram baixos desempenhos per se, e baixa estabilidade, com altos valores de $\mathrm{W}_{\mathrm{i}}$, tendo AGR 08 a pior média per se e o AGR 18 comportamento diferente entre os ambientes (Tabela 2).

Não foi possível detectar diferenças pelo teste de Tukey a 5\% de probabilidade para os híbridos avaliados entre os diferentes ambientes em relação a Massa Média dos frutos (Tabela 2). Entretanto, observando os desempenhos per se dentro de cada ambiente, os híbridos AGR 28 e AGR 32 destacaram-se, uma vez que possuíam maiores médias em ambos ambientes e alta estabilidade, com $\mathrm{W}_{\mathrm{i}}=0,28$ e $\mathrm{W}_{\mathrm{i}}=0,09$ respectivamente, junto com a testemunha TPX 4460, com alta média per se e boa estabilidade. Assim como as testemunhas TPX 903 e Santa Cruz 47, os híbridos AGR 08 e AGR 18, mesmo possuindo boa estabilidade $\mathrm{W}_{\mathrm{i}}=0,11$ e $\mathrm{W}_{\mathrm{i}}=0,35$ respectivamente, não obtiveram os maiores desempenhos per se para o experimento cultivado em MG (Tabela 2). Segundo Franceschi et al. (2010) essa metodologia recomenda cultivares estáveis independentemente do rendimento e da responsividade aos ambientes. $\mathrm{Na}$ avaliação do desempenho produtivo e interação genótipo $\mathrm{x}$ ambiente em híbridos e linhagens de mamoeiro, Oliveira et al. (2014) constataram que nem todos os genótipos de maior estabilidade possuíam melhor desempenho per se para as variáveis avaliadas.

Em relação à produtividade, os híbridos AGR 11, AGR 28 e AGR 32, destacaram-se por possuírem ótimo desempenho per se para cada ambiente e comportamento igual entre os ambientes, com alta estabilidade, sendo muito similares às testemunhas comerciais TPX 903, TPX 4460 e Santa Cruz 47, com destaque para o híbrido AGR 28, uma vez que possuí as maiores médias per se dentro de cada ambiente, com baixo valor de $\mathrm{W}_{\mathrm{i}}(\%)=$ 0,19 , podendo ser indicado para cultivo em regiões representativas aos locais onde os experimentos foram conduzidos, uma vez que possuem ótimo desempenho per se e alta estabilidade fenotípica.

Em contrapartida, os híbridos AGR 18 e AGR 19, mesmo obtendo bons comportamentos per se dentro de cada ambiente para Massa Total de frutos, são híbridos com menores estabilidades, uma vez que obtiveram maiores valores de $\mathrm{W}_{\mathrm{i}}$, e devem ter sua indicação de cultivo para regiões específicas, segundo metodologia proposta por Wricke (1956).

Com base nos resultados obtidos é possível recomendar híbridos que atendam às diferentes necessidades dos agricultores famíliares, para diferentes regiões onde o quiabeiro é cultivado.

\section{CONCLUSÕES}

Houveram diferentes desempenhos dos híbridos avaliados nos ambientes estudados.

Os híbridos AGR 28 e AGR 32 podem ser indicados para cultivos em diferentes regiões representativas onde os experimentos foram realizados.

\section{LITERATURA CITADA}

AGUIAR, F.M.; MICHEREFF, S.J.; BOITEUX, L.S. et al. Search for sources of resistance to Fusarium wilt (Fusarium oxysporum f. sp. vasinfectum) in okra germplasm. Crop Breeding and Applied Biotechnology, v.13, n.1, p.33-40, 2013.

ALADELE, S.E.; ARIVO, O.J; LAPENA, R. Genetic relationship among west African okra (Abelmoschus caillei) and Asian genotypes (Abelmoschus esculentum) using RAPD. African Journal of Biotechnology, v.7, n.10, p.1426, 2008. 
BURATTO, J.S.; MODA-CIRINO, V.; JÚNIOR, N.D.S.F. et al. Agronomic performance and grain yield in early common bean genotypes in Paraná state. Semina: Ciências Agrárias, v.28, n.3, p.373-380, 2007.

CRUZ, C.D. GENES, a software package for analysis in experimental statistics and quantitative genetics. Acta Scientiarum. Agronomy, v.35, n.3, p.271-276, 2013.

CRUZ, C.D.; REGAZZI, A.J.; CARNEIRO, P.C.S. Modelos biométricos aplicado ao melhoramento de genético. Viçosa: MG: UFV, 2012.514p.

MEDAGAM, T.R.; KADIYALA, H., MUTYALA, G. et al. Heterosis for yield and yield components in okra (Abelmoschus esculentus (L.) MOENCH).

Chilean Journal of Agricultural

Research, v.72, n.3, p.316-325, 2012.

NUNES, G.H.S.; RESENDE, G.D.S.P.; RAMALHO, M.A.P. et al. Implicações da interação genótipo x ambientes na seleção de clones de eucalipto. Cerne, v.8, n.1, p.49-58, 2002.

NUNES, G.H.S.; MADEIROS, A.G.S.; GRANGEIRO, L.C. et al. Estabilidade fenotípica de híbridos de melão amarelo avaliados no Pólo Agrícola Mossoró-Assu. Pesquisa Agropecuária Brasileira, v.41, n.9, p.1369-1376, 2006.

OLIVEIRA, E.J.; FRAIFE FILHO, G.A.; FREITAS, J.P.X. et al. Desempenho produtivo e interação genótipo X ambiente em híbridos e linhagens de mamoeiro. Bioscience Journal, v.30, n.2, p.402-410, 2014.
PAIVA, W.O.; COSTA, C.P. Parâmetros genéticos em quiabeiro. Pesquisa Agropecuária Brasileira, v.33, n.5, p.705-712, 1998.

PAIVA, W.O.; COSTA, C.P. Estabilidade de híbridos e cultivares de quiabeiro. Pesquisa Agropecuária Brasileira, v.29, n.5, p.791796, 1994.

POLIZEL, A.C.; JULIATTI, F.C.; HAMAWAKI, O.T. et al. Adaptabilidade e estabilidade fenotípica de genótipos de soja no estado do Mato Grosso.

Bioscience Journal, v.29, n.4, 2013.

RAMALHO, M.A.P.; ABREU, A.F.B.; SANTOS, J.B. et al. Aplicações da genética quantitativa no melhoramento de plantas autógamas. Lavras, Ed. UFLA, 2012, 522p.

SEDIYAMA, M.A.N.; SANTOS, M.R.; VIDIGAL, S.M. et al. Produtividade e estado nutricional do quiabeiro em função da densidade populacional e do biofertilizante suíno. Bragantia, Campinas, v.68, n.4, p.913-920, 2009.

TRANI, P.E.; PASSOS, F.A.; TEODORO, M.C.C.L. et al. Calagem e adubação para a cultura do quiabo. 2012. $4 \mathrm{p}$.

WRICKE, G. Zur berechnung der okovalenz bei sommerweizen und hafer. Zeitschrift fur pflanzenzuchtung - Journal of Plant Breeding, v.52, n.2, p.127-\&, 1964.

YUAN, C.Y.; ZHANG, C.; WANG, P. et al. Genetic diversity analysis of okra (Abelmoschus esculentus L.) by inter-simple sequence repeat (ISSR) markers. Genetics and Molecular Research, v.13, n.2, p.3165-3175, 2014.

Recebido para publicação em 03/03/2017 e aprovado em 30/05/2017. 